\title{
Early repolarization syndrome and left ventricular muscle band; a case-control study
}

Rezvanyeh Salehi ${ }^{1}$, Babak Kazemi $^{1}$, Zahra Jabbari ${ }^{{ }^{*}}$

1. Cardiovascular Research Center, Department of Cardiology, Shahid Madani Tertiary Heart Center, Tabriz University Of Medical Sciences, Tabriz, I.R.Iran

\begin{abstract}
Background and objective: The left ventricular false band (LVFB) is a discrete, fibromuscular structure that traverses the left ventricular cavity. Some LVFBs contain longitudinal conduction tissues suggesting that they may contribute to the occurrence of ventricular arrhythmias. Few recent studies have suggested an association between early repolarization and the presence of LVFB previously. Due to lack of insufficient supporting data, however, further studies are needed in this regard. So the present work sought to investigate a possible relation between the LVFB and early repolarization. Methods \& Materials: A total of 45 patients with early repolarization (cases) and 45 age- and sex-matched controls (without early repolarization) were recruited from Madani Teaching Heart Center during a 17-month period of time. Subjects with acute or chronic ischemic heart disease and those with cardiac valve disease were not included. Frequency of echocardiographically detected LVFBs, as well as their number, size and location were compared between the two groups. Results: Both the case and the control groups comprised 44 males and 1 female. The mean age of patients in the case group was $29.7 \pm 8.8$ years (range: $15-51$ ) vs. $30.0 \pm 9.0$ years (range: $15-53$ ) in the control group ( $p=0.87$ ). While the LVFB was more common in the case than in the control group, the difference did not reach a statistical level of significance $(8.9 \%$ vs. $6.7 \%, p=0.5)$. The two groups were comparable for the number $(p=0.1)$, length $(p=0.77)$, width $(p=0.38)$ and location of the LVFBs ( $p$ indefinable). Conclusion: In the present work the LVFB was more common in patients with than without early repolarization, however, the difference was not statistically significant. Further studies with larger sample sizes are needed.
\end{abstract}

Keywords: Left Ventricular Fibrous Band; Early Repolarization; Echocardiography;

Department of Cardiology, Shahid Madani Tertiary Heart Center, Tabriz University of Medical Sciences, Daneshgah St, Golgasht St, Tabriz, Iran. 51665 e-mail: dr.z.jabbary@gmail.com

Receive date: 2016-09-7| Accept date: 2016-10-10| Publish date: 2016-11-12

DOI: 10.7575/aiac.abcmed.16.04.04.02 


\section{Introduction}

Clinical syndromes present as J wave slurring and ST segment elevation in healthy individuals without structural cardiac disease include early repolarization syndrome (ERS), Brugada syndrome, and idiopathic ventricular fibrillation (1).

ERS was first described as an electrocardiographic phenomenon almost half a century ago. This condition is recognized as an electrocardiographic pattern of benign, innocent, misleading, idiopathic ventricular repolarization that affects $1-2 \%$ of the general population, mostly among the young. The incidence has been reported higher in males than in females $(2,3)$.

This syndrome is found as an electrocardiographic pattern including J wave slurring, ST segment elevation and symmetrical high-voltage $T$ waves frequently in left lateral leads and less commonly in inferior leads. The clinical significance of ERS is only making trouble for diagnostic purposes (412).

The left ventricular false band (LVFB) is a discrete, fibromuscular structure with various length and thickness that crosses through the left ventricle (13). Although LVFTs are generally considered as benign findings (14, 15), previous reports have suggested multiple abnormalities in connection with them, such as precordial murmurs (16), abnormal repolarization in resting electrocardiograms (17), ventricular arrhythmias (18), mitral valve insufficiency, and left ventricular dilation (19). It should be born in mind, however, that the data supporting an association between LVFTs and the proposed abnormalities are limited and the possibility of this relationship between LVFTs and ventricular arrhythmias/repolarization abnormalities is still under dispute (20-22).
So, the present study aimed to examine a possible connection between LVFTs and ERS.

\section{Materials and methods}

\section{Study design and patients}

In this case-control study, a total of 45 patients with ERS (cases) and 45 patients without ERS (controls) were compared in terms of the frequency of LVFT in Tabriz Madani Heart Hospital from October 2013 through to March 2014. Written informed consents were obtained from the participants.

The Ethics Committee of the Tabriz University of Medical Sciences approved this study. The exclusion criteria were as follows: congenital heart disease, hypertension, acute or chronic ischemic heart disease, and valvular heart problems. The two groups for comparable for age and sex of participants. electrocardiographic study Standard 12-lead surface digital ECGs were recorded in subjects resting in supine position. The employed electrocardiographic device was Cardiofax (Nihon Kohden, Tokyo, Japan) equipped with a $100 \mathrm{~Hz}$ low-pass filter. The used resolution was $1.25 \mu \mathrm{V}$ with a range of 16 bits. J-waves were reported as either slurring (a smooth transition from the QRS to the ST segment) or notching (a positive deflection) with an amplitude of $\geq 0.1 \mathrm{mV}$ on the terminal QRS portion in at least two of the inferior (II, III, aVF) or the lateral leads (I, aVL, and V4 through V6) (23). ERS was reported when J wave and ST segment elevation were present on standard 12-lead precordial electrocardiograms.

\section{Echocardiographic study}

Patients were examined for the presence of LVFT(s) using a standard two-dimensional echocardiography (Vivid 7, GE Healthcare UK Ltd, Buckinghamshire, England) equipped with an M3S probe. The studies included standard parasternal long and short axis, apical 2, 3, and 4 chamber, and subcostal views. Off-axis 
parasternal and apical views were also recorded to determine the LVFT orientation and insertion points. Two echocardiography experts who were unaware of ECG findings reviewed digitally stored images, independently. In case of discrepancy, a third echocardiography expert was arbitrated. The LVFTs were defined as linear cordlike fibromuscular structures that crossed the LV cavity without attachment to the mitral valve leaflets (23). (Figure 1). Location, number, and size (width and length) of LVFT(s) were also reported and compared between the case and control groups.

\section{Statistical analysis}

Data were presented as mean \pm standard deviation or frequency (\%), using the SPSS software version 16.0. A normal distribution of the numerical data was tested using the Kolmogorov-Smirnov test. Independent

(case) and without (control) early repolarization syndrome

\begin{tabular}{|c|c|c|c|}
\hline \multirow[t]{2}{*}{ Variable } & \multicolumn{2}{|c|}{ Group } & \multirow{2}{*}{$\begin{array}{c}\text { p- } \\
\text { Value }\end{array}$} \\
\hline & $\begin{array}{l}\text { Case } \\
(n=45)\end{array}$ & $\begin{array}{l}\text { Control } \\
(n=45)\end{array}$ & \\
\hline \multicolumn{4}{|l|}{ Number } \\
\hline 1 & $1(2.2)$ & $3(6.7)$ & 0.14 \\
\hline 2 & $3(6.7)$ & $0(0)$ & \\
\hline \multirow[t]{2}{*}{ Length (mm) } & $28.7[19.4-$ & $29.0[28-$ & 0.77 \\
\hline & $34.4]$ & 30] & \\
\hline \multirow[t]{2}{*}{ Maximum length (mm) } & $28.9[28-34]$ & $29.0[28-$ & 0.81 \\
\hline & & 30] & \\
\hline Width (mm) & $3.0[2.5-5]$ & $4.2[3.4-5]$ & 0.38 \\
\hline Maximum width (mm) & $3.5[3-5]$ & $4.2[3.4-5]$ & 0.69 \\
\hline \multicolumn{4}{|l|}{ Location } \\
\hline $1 / 3$ distal of the lateral wall- $1 / 3$ distal of the & $4(8.9)$ & $3(6.7)$ & - \\
\hline septum & & & \\
\hline Mid lateral wall-mid septum & $2(4.4)$ & $0(0)$ & \\
\hline $1 / 3$ distal of the lateral wall-mid septum & $1(2.2)$ & $0(0)$ & \\
\hline
\end{tabular}

Data are presented as frequency (\%) or median [range].

Table 1: Number, size and location of left ventricular false band(s) detected in patients with Characteristics of the LVFB(s) found in cases and controls are summarized and compared between the two groups in Table 1. The two groups were comparable in terms of the number, size and location of the LVFBs. 


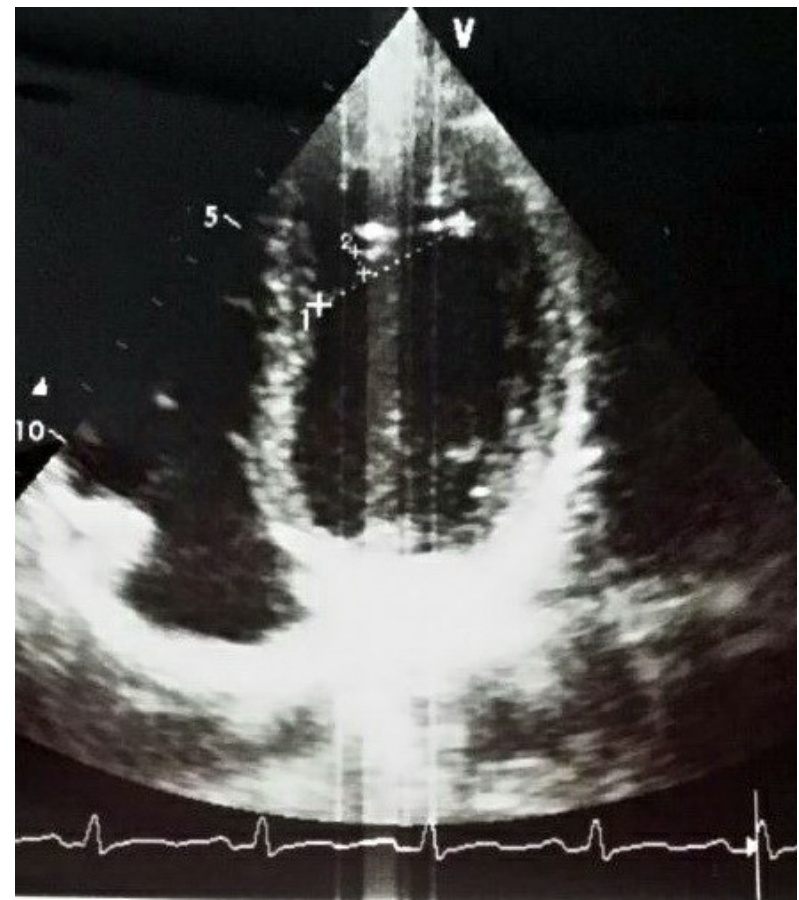

Figure 1: A sample of left ventricular false band found in a patient with echocardiography

samples $\mathrm{t}$ test/Mann-Whitney $\mathrm{U}$ test and chi-square/Fisher's exact test was used for the comparison of quantitative and qualitative data, respectively. A $p$-Value $\leq 0.05$ was considered statistically significant.

\section{Results}

Patients in both case and control groups were 44 males $(97.8 \%)$ and 1 female $(2.2 \%)$. The two groups were comparable for patients' age $(29.7 \pm 8.8$ years, range, $15-51$ in cases, $30.0 \pm 9.0$ years, range, $15-53$ in controls; $\mathrm{p}=0.87)$. LVFB was detected in 4 patients $(8.9 \%)$ in the case group and in 3 patients (6.7\%) in the control group, with no significant difference between them $(p=0.50)$.

\section{Discussion}

According to available reports, LVFB is present in $50 \%$ of the general population (14, $24)$, and in some cases may contain conductive tissue (25) sometimes along with the bundle of Hiss. On this basis, its presence may sometimes result in cardiac arrhythmias, such as ERS. So, the present study aimed to examine a possible connection between the presence of $\operatorname{LVFB}(s)$, as well as its number, size and location with the occurrence of ERS. Accordingly, although LVFBs were seen more frequently in ERS than in control group ( $8.9 \%$ vs. $6.7 \%)$, no significant difference was found in this regard $(p=0.50)$.

The related available data are heterogeneous in the literature. In a study conducted by Fengying et al (26), 30 patients with ERS and 50 controls were examined for the presence of $\operatorname{LVFB}(\mathrm{s})$. In conformity with our finding, they did not find a significant difference in this regard between the groups. In contrast, in a series by Nakagawa et al (27), J waves were detected more frequently on electrocardiograms belonging to 44 patients with LVFB compared to those in 88 subjects without LVFB. The same group in another study (23) examined 50 healthy young males (mean age, 24.6 years), and the presence of LVFB(s) was tested by using echocardiography. At the same time, a J wave slurring ( $0.1 \mathrm{mV}$ or more) at the end of QRs complexes was also looked for on standard electrocardiograms. Accordingly, LVFB(s) were found in $74 \%$ of the subjects, and J wave slurring occurred more frequently in patients with $\operatorname{LVFB}(\mathrm{s})$. They suggested that the presence of $\operatorname{LVFB}(\mathrm{s})$ might cause cardiac conductive delays.

Various causes could justify these heterogeneous results. Patients' age, level of physical activity, employed echocardiography device and using or not using filters have been found influential in this regard. For example, it has been shown that $J$ waves are seen more commonly in male athletes (28).

In postmortem studies performed by Luetmer et al (14) and Loukas et al (24), LVFB(s) was found in $55-62 \%$ of male and female cadavers. The incidence of LVBF in our series was lower than these figures. Previously mentioned justifications may explain this inconformity. 
In the present work, we did not find any association between number, size and location of LVFB(s) and ERS development. In contrast, Fengying et al (26) suggested that the location of $\operatorname{LVBF}(\mathrm{s})$ may play a significant role in propagation of ERS. At the same time and in conformity with our results, they also did not find an association between ERS occurrence and the number of LVFB(s). In another study by Nakagawa et al (23), it was shown that the frequency of J waves was significantly higher in a group of patients with type I (longitudinal) or type II (diagonal) LVFB(s) compared to those with type III (transverse) LVFB(s) or without $\operatorname{LVFB}(\mathrm{s})$. In multivariate analysis, however, the only predictor of $J$ wave occurrence was the presence of LVFB(s). In another study by Nakagawa et al (27) it was shown that the frequency of $J$ waves in patients with thick $\operatorname{LVFB}(\mathrm{s})(2 \mathrm{~mm} \leq)$ was higher than those with thin LVFB(s). This finding is in contrast with our result that detected no significant difference between the case and control groups for the size of LVFB(s). Maybe, a small sample size underlies this discrepancy. Further studies using larger number of patients may lead to more solid conclusions.

Although the exact mechanism of $\mathrm{J}$ wave occurrence is unclear, experimental and clinical evidences suggest the presence of anomalies in late depolarization or early repolarization (2934). Two theories have been though in this regard: i) if transverse or diagonal LVFBs contain longitudinal conductive tissues similar to the bundle of Hiss, electrical activity could be conducted through such LVFBs from the septum toward the free lateral or left inferior ventricular walls. This conduction, however, is slower than normal condition and could be deviated inferolaterally, leading to the emergence of delayed activities in terminal parts of QRS complex in inferior or lateral leads; ii) a focal repolarization gradient developed by stretched purkinje fibers or their undetermined activity may play a role in this regard (23). So, histopathologic examination of LVFBs in cadavers may result in drawing more exact conclusions

In terms of the presence or absence of conductive tissues inside these structures and a possible connection between LVF and ERS. In addition, three dimensional/intracardiac echocardiography and magnetic resonance imaging (MRI) could be used for more precise determination of LVFB intracardaic attachments.

\section{References}

1. Shu J, Zhu T, Yang L, Cui C, Yan GX. ST-segment elevation in the earlyrepolarization syndrome, idiopathic ventricular fibrillation, and the Brugada syndrome: cellular and clinical linkage. Journal of electrocardiology. 2005;38(4 Suppl):2632.

2. Martinez-Lopez JI. ECG of the month. Innocent abnormality. Early repolarization pattern. The Journal of the Louisiana State Medical Society: official organ of the Louisiana State Medical Society. 1991;143(11):7, 9-10.

3. Gussak I, Antzelevitch C. Early repolarization syndrome: clinical characteristics and possible cellular and ionic mechanisms. Journal of electrocardiology. 2000;33(4):299-309. 
4. Eastaugh JA. The early repolarization syndrome. The Journal of emergency medicine. 1989;7(3):257-62.

5. Saviolo R, Spodick DH. Electrocardiographic responses to maximal exercise during acute pericarditis and early repolarization. Chest. 1986;90(3):460-2.

6. Wanner WR, Schaal SF, Bashore TM, Norton VJ, Lewis RP, Fulkerson PK. Repolarization variant vs acute pericarditis. A prospective electrocardiographic and echocardiographic evaluation. Chest. 1983;83(2):180-4.

7. Kambara H, Phillips J. Long-term evaluation of early repolarization syndrome (normal variant RS-T segment elevation). The American journal of cardiology. 1976;38(2):157-6.

8. Vorob'ev LP, Gribkova IN, Petrusenko NM, Trofimenko NB. [The clinico-electrocardiographic classification of the early ventricular repolarization syndrome]. Terapevticheskii arkhiv. 1992;64(3):93-7.

9. Bjornstad H, Storstein L, Dyre Meen H, Hals O. Electrocardiographic findings according to level of fitness and sport activity. Cardiology. 1993;83(4):268-79.

10. Hollander JE, Lozano M, Fairweather P, Goldstein E, Gennis P, Brogan GX, et al."Abnormal" electrocardiograms in patients with cocaine-associated chest pain are due to "normal" variants. The Journal of emergency medicine. 1994;12(2):199-205.

11. Guillem JP, Haissaguerre M, Lemetayer P, Montserrat P, Le Herissier A, Warin JF. [Echocardiographic study of the early repolarization syndrome. Demonstration of dynamic obstruction with isoprenaline. Apropos of 16 cases]. Archives des maladies du coeur et des vaisseaux. 1988;81(2):199-206.

12. Antonov OS, Korzhenkov AA, Kuznetsov VA, Liutova FF. [Accessory left-ventricular chorda and the early ventricular repolarization syndrome]. Kardiologiia. 1988;28(9):82-4.

13. Nishimura $T$, Kondo $M$, Umadome $H$, Shimono $Y$. Echocardiographic features of the false tendons in the left ventricle. The American journal of cardiology. 1981;48(1):177-83.

14. Luetmer PH, Edwards WD, Seward JB, Tajik AJ. Incidence and distribution of left ventricular false tendons: an autopsy study of 483 normal human hearts. Journal of the American College of Cardiology. 1986;8(1):179-83.

15. Gerlis LM, Wright HM, Wilson N, Erzengin F, Dickinson DF. Left ventricular bands. A normal anatomical feature. British heart journal. 1984;52(6):641-7.

16. Gardiner HM, Joffe HS. Genesis of Still's murmurs: a controlled Doppler echocardiographic study. British heart journal. 1991;66(3):217-20.

17. Salazar J. Left ventricular anomalous muscle band and electrocardiographic repolarization changes. Pediatric cardiology. 1997;18(6):434-6.

18. Suwa M, Yoneda $Y$, Nagao H, Sakai $Y$, Nakayama $Y$, Hirota $Y$, et al. Surgical correction of idiopathic paroxysmal ventricular tachycardia possibly related to left ventricular false tendon. The American journal of cardiology. 1989;64(18):1217-20.

19. Keren A, Billingham ME, Popp RL. Ventricuar aberrant bands and hypertrophic trabeculations. A clinical pathological correlation. The American journal of cardiovascular pathology. 1988;1(3):369-78.

20. Silbiger JJ. Left ventricular false tendons: anatomic, echocardiographic, and pathophysiologic insights. Journal of the American Society of Echocardiography: official publication of the American Society of Echocardiography. 2013;26(6):582-8.

21. Silbiger JJ. The role of shear stress in the pathogenesis of discrete subaortic stenosis: implications for surgical treatment. The Journal of heart valve disease. 2011;20(2):123-8.

22. Mirzoyev S, McLeod CJ, Asirvatham SJ. Embryology of the conduction system for the electrophysiologist. Indian pacing and electrophysiology journal. 2010;10(8):329-38.

23. Nakagawa M, Ezaki K, Miyazaki H, Ebata $\mathrm{Y}$, Shinohara T, Teshima $\mathrm{Y}$, et al. False tendons may be associated with the genesis of J-waves: prospective study in young healthy male. International journal of cardiology. 2014;172(2):428-33. 
24. Loukas M, Louis RG, Jr., Black B, Pham D, Fudalej M, Sharkees M. False tendons: an endoscopic cadaveric approach. Clinical anatomy. 2007;20(2):163-9.

25. Kervancioglu M, Ozbag D, Kervancioglu P, Hatipoglu ES, Kilinc M, Yilmaz F, et al.Echocardiographic and morphologic examination of left ventricular false tendons in human and animal hearts. Clinical anatomy. 2003;16(5):389-95.

26. Fengying Y, Yong C, Minhua G. Study on relationship between early repolarization syndrome and left ventricular fibromuscular bands. Chinese Journal of Ultrasound Diagnostic. 2004; 9:65-72.

27. Nakagawa M, Ezaki K, Miyazaki H, Wakisaka O, Shinohara T, Teshima Y, et al. Electrocardiographic characteristics of patients with false tendon: possible association of false tendon with J waves. Heart rhythm: the official journal of the Heart Rhythm Society. 2012;9(5):782-8.

28. Garcia-Niebla J, Serra-Autonell G. Effects of inadequate low-pass filter application. Journal of electrocardiology. 2009;42(4):303-4.

29. Antzelevitch C, Yan GX. J wave syndromes. Heart rhythm : the official journal of the Heart Rhythm Society. 2010;7(4):549-58.

30. Boineau JP. The early repolarization variant--normal or a marker of heart disease in certain subjects. Journal of electrocardiology. 2007;40(1):3 e11-6.

31. Borggrefe $M$, Schimpf R. J-wave syndromes caused by repolarization or depolarization mechanisms a debated issue among experimental and clinical electrophysiologists. Journal of the American College of Cardiology. 2010;55(8):798-800.

32. Rosso R, Adler A, Halkin A, Viskin S. Risk of sudden death among young individuals with J waves and early repolarization: putting the evidence into perspective. Heart rhythm: the official journal of the Heart Rhythm Society. 2011;8(6):923-9.

33. Antzelevitch C. Genetic, molecular and cellular mechanisms underlying the J wave syndromes. Circulation journal: official journal of the Japanese Circulation Society. 2012;76(5):1054-65.

34. Nam GB. Idiopathic ventricular fibrillation, early repolarization and other J wave- related ventricular fibrillation syndromes: from an electrocardiographic enigma to an electrophysiologic dogma. Circulation journal: official journal of the Japanese Circulation Society. 2012;76(12):2723-31. 